\title{
Insular cortex dopamine 1 and 2 receptors in methamphetamine conditioned place preference and aversion: Age and sex differences
}

\author{
Ellen Rose Cullity ${ }^{\circledR 1,2}$, Alexandre Arthur Guérin (i1) ${ }^{1,2}$, Heather Bronwyn \\ Madsen (i) ${ }^{1}$, Christina Jennifer Perry ${ }^{10}{ }^{1,2}$ and Jee Hyun Kim ${ }^{1} 1,2,3$,*
}

\author{
${ }^{1}$ Mental Health Theme, Florey Institute of Neuroscience and Mental Health, Melbourne, Victoria, Australia ${ }^{\prime}{ }^{\prime}$ \\ ${ }^{2}$ The Florey Department of Neuroscience and Mental Health, The University of Melbourne, Melbourne, Australia $R$. \\ ${ }^{3}$ IMPACT - the Institute for Mental and Physical Health and Clinical Translation, School of Medicine, Deakin \\ University, Geelong, VIC, Australia ${ }^{\prime \prime}$ \\ *drjeehyunkim@gmail.com
}

\begin{abstract}
Rodent studies have proposed that adolescent susceptibility to substance use is at least partly due to adolescents experiencing reduced aversive effects of drugs compared to adults. We thus investigated methamphetamine (meth) conditioned place preference/aversion (CPP/CPA) in adolescent and adult mice in both sexes using a high dose of meth ( $3 \mathrm{mg} / \mathrm{kg})$ or saline as controls. Mice tagged with green-fluorescent protein (GFP) at Drd1a or Drd2 were used so that dopamine receptor 1 (D1) and 2 (D2) expression within the insular cortex (insula) could be quantified. There are sex differences in how the density of D1+ and $\mathrm{D} 2+$ cells in the insula changes across adolescence that may be related to drug-seeking behaviors. Immunohistochemistry followed by stereology were used to quantify the density of cells with c-Fos and/or GFP in the insula. Unexpectedly, mice showed huge variability in behaviors including CPA, CPP, or no preference or aversion. Females were less likely to show CPP compared to males, but no age differences in behavior were observed. Conditioning with meth increased the number of D2 + cells co-labelled with c-Fos in adults but not in adolescents. D1:D2 ratio also sex- and age-dependently changed due to meth compared to saline. These findings suggest that reduced aversion to meth is unlikely an explanation for adolescent vulnerability to meth use. Sex- and age-specific expressions of insula D1 and D2 are changed by meth injections, which has implications for subsequent meth use.
\end{abstract}

Related Objects: Dataset - https://doi.org/10.5281/zenodo.4983499

Key words: Adolescence; Dopamine; Insula; Methamphetamine; Sex differences

Abbreviations: ANOVA, analysis of variance; CPA, conditioned place aversion; CPP, conditioned place preference; D1, dopamine receptor 1; D2, dopamine receptor 2; GENSAT, Gene Expression Nervous System Atlas; GFP, green fluorescent protein; i.p,. intraperitoneal; meth, methamphetamine; NDS, normal donkey serum; P, postnatal day; PB, phosphate buffer; PBS, phosphate buffered saline; PFA, paraformaldehyde; RM, repeated measures; SD, standard deviations

\section{Introduction}

Methamphetamine (meth) is a highly addictive amphetaminetype psychostimulant that is the second most commonly used illicit drug in the world [1]. Youth use is a major concern [1-3]. For example, over $5 \%$ of Australians aged 14-19 have reported using methamphetamine in the last 12 months [4]. Compared to other addictive substances, prevalence of meth use in males is not al- ways higher than females [5-8], and females begin using meth earlier and transition more rapidly from initial to problematic meth use [9-13]. These observations indicate that both age and sex are important factors in meth use disorder. However, sex- and agedependent effects of meth on brain and behavior are poorly understood. 
Addictive substances have not only rewarding but also aversive properties, and it has been proposed that adolescent susceptibility to drug use is due to their reduced aversive experience to substances [14]. Rodent evidence suggests that adolescents are less sensitive than adults to the aversive effects of amphetamine, cocaine, nicotine, and ethanol [15-19], a finding that may extend to meth. Conditioned place preference or aversion (CPP or CPA) is widely used to study the preference or aversion to substances in rodents [20-22]. The procedures for these paradigms are essentially identical, with subjects learning to associate environmental cues with a drug experience by receiving drug in one distinct chamber and saline in another distinct chamber. When given unrestricted access to both chambers without any drug, CPP is operationalised as a significantly greater amount of time spent in the drug-paired, compared to the saline-paired, context. In contrast, CPA is operationalised as spending significantly less time in the drug-paired, compared to saline-paired, context.

Our aim was to assess potential CPA or CPP using a high dose of meth in adolescent and adult male and female mice, and then to examine dopamine receptors 1 (D1) and 2 (D2) expression in the insular cortex (commonly referred to as insula). How these receptors are involved in meth CPA (or CPP) are poorly understood, especially in the context of adolescence. D1 and D2 expression changes throughout development in rodents and humans [23-25], which has consequences on local excitatory and inhibitory control [26]. Differences between adults and adolescents in D1 and D2 expression in cortical regions have been proposed to explain adolescent vulnerability to mental disorders, including in substance use disorders [27]. Our recent comprehensive stereological investigation showed that of many cortical regions, the insula showed the most dramatic changes in D1 and D2 expression across adolescence in male and female mice [28, for data see 29-36]. Specifically, females show D1 dominance in adolescence to adulthood, whereas males show D1 and D2 balance in adolescence that changes to D1 dominance in adulthood [28]. Activation of D1 stimulates, whereas D2 inhibits adenylyl cyclase [37]. D1 agonist has been shown to induce CPA, whereas D2 agonist has been shown to induce CPP in adult male rats $[38,39]$. D1 and D2 antagonists have been shown to block amphetamine-induced CPP in adult male rats [40]. Taken together, D2 appears necessary and sufficient for amphetamineinduced CPP, while D1 may be important for CPA and CPP. Interestingly, injection of the partial D2 antagonist olanzapine in adolescence can enhance amphetamine-induced CPP in adulthood, which was associated with reduced D1 and increased D2 binding [41]. Insula activation has been shown to be critical for long-term memory of CPP [42]. Based on previous findings on the necessity of D1 signaling in CPA, we hypothesized that the lack of D1 dominance in the insula of male adolescents may lead to reduced meth CPA compared to females and male adults.

Taken together, potential age and sex differences in meth CPA/CPP, and related activation of cells expressing D1 and D2 within the insular cortex were investigated in this study using validated transgenic mice expressing green fluorescent protein (GFP) tagged D1 or D2 [43]. Postnatal day (P) 49 and P70 mice were used in this study because the biggest sex differences in insula D1 and D2 expression were observed at P49 [28]. In fact, latest rodent hormonal and cognitive development studies state that P49 corresponds to mid adolescence [44], which is appropriate given the pattern of meth use in humans that begin first in mid to late adolescence $[3,45]$. In female mice, ovulation and vaginal opening are not correlated, with first ovulation at $\sim \mathrm{P} 42$ [46] and regular estrous cycling typically not observed until P60 [47]. In swiss mice used in this study, P30 is considered pre-pubertal [48], with first estrus cycle observed 10 days (i.e., P40) after vaginal opening [49]. In male mice, average age of prepuce-glans separation is $\sim 236[50]$. Thus, 'adolescent' will refer to mid adolescent $\mathrm{P} 49$ mice in this study. To minimize the maturation that occurs during CPA/CPP, we used a previously published 4-day conditioning protocol that involved a saline injection each morning and a meth injection each afternoon [51, 52], which is considerably shorter than a typical CPA/CPP protocol in mice [53]. We hypothesized that male, but not female, adolescents would display less CPA and more CPP compared to adult male and female mice that will show comparable CPA and CPP based on their balance between D1 and D2 expression in insula.

\section{Materials and Methods}

\subsection{Animals}

All experimental procedures were approved by the Florey Institute's Animal Ethics Committee and performed in accordance with the Australian code for the care and use of animals for scientific purposes. The mice came from separate breeding colonies where female and male Drd1a-EGFP (D1) and Drd2-EGFP (D2) hemizygous mice were mated, all bred on an outbred $\operatorname{Arc:Arc(S)~Swiss~back-~}$ ground, established and housed in a common colony room at the Florey Institute of Neuroscience and Mental Health, Melbourne, Australia. Mice were originally generated by the Gene Expression Nervous System Atlas (GENSAT) program at the Rockefeller University, New York, USA [43]. Only mice hemizygous for the EGFP reporter gene were used in the study - wildtype and homozygous littermates were culled after genotyping at weaning. Homozygous mice have been to show overexpression of the tagged receptor [54] while hemizygous mice are indistinguishable from wildtype counterparts [55]. Mice were postnatal day (P) 49 \pm 2 (referred to as 'adolescent' throughout this paper) or $\mathrm{P} 70 \pm 4$ (referred to as adult throughout this paper) on day 1 of behavior. Mice were weaned at P18-P21 and were housed in same-sex groups of 3-5 littermates in open-top cages ( $34 \mathrm{~cm} \mathrm{x} 16 \mathrm{~cm} \mathrm{x} 16 \mathrm{~cm}$ ) maintained on a $12 \mathrm{~h}$ light/dark cycle (lights on at 07:00) in a temperature-controlled $\left(22 \pm 1.5^{\circ} \mathrm{C}\right)$ environment. Food (standard chow: Barastoc, VIC, Australia) and water were available ad libitum.

\subsection{Genotyping}

Mouse pups were genotyped using PCR. DNA was extracted from tail samples using the REDExtract-N-AMP ${ }^{\mathrm{TM}}$ Tissue PCR Kit (Cat\#: XNAT-100RXN, Sigma-Aldrich) and PCR was performed using GoTaq ${ }^{\circledR}$ Green Master Mix (Cat\#: M7122, Promega) according to recommended protocols. Primers were purchased from $\mathrm{Ge}-$ neworks. The following forward and reverse primers were used:

\footnotetext{
- Drd1a-EGFP forward primer: 5'-ACC GGA AGT GCT TTC CTT CTG GA-3'

- Drd1a-EGFP reverse primer: $5^{\prime}$-TAG CGG CTG AAG CAC TGC A-3'

- Drd2-EGFP forward primer: $5^{\prime}$-GAG GAA GCA TGC CTT GAA AA-3'

- Drd2-EGFP reverse primer: 5 '-TGG TGC AGA TGA ACT TCA GG-3'
}

\subsection{Methamphetamine}

Methamphetamine (meth) was obtained from Sigma-Aldrich Australia Pty Ltd (Castle Hill, NSW, Australia; purity ${ }^{3} 98 \%$ ) and dissolved in $0.9 \%$ saline. The volume of intraperitoneal (i.p.) injection was $10 \mathrm{ml} / \mathrm{kg}$. The dose of meth used in this experiment was $3 \mathrm{mg} / \mathrm{kg}$ to encourage development of conditioned place aversion (CPA). Since we were mainly interested in whether there were distinctions between sexes and ages in the aversive properties of meth, we chose a dose that was higher (and therefore likely more aversive) than that used previously in mice CPP studies [51, 52, 56, 57]. In addition, pilot experimentation showed daily injections of 6-9 


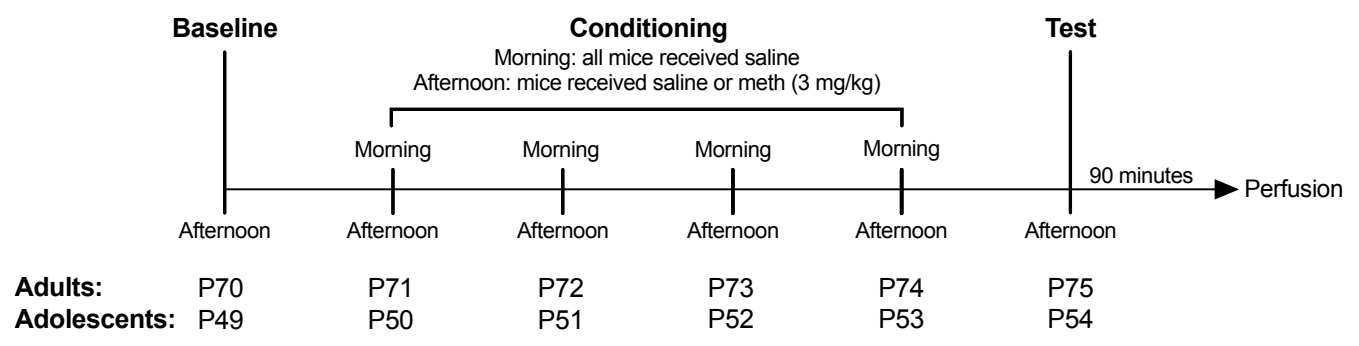

Figure 1. Experiment timeline. Mice numbers ( $n$ ) for meth group: adolescent male $n=27$, adolescent female: $n=19$; adult male: $n=24$; adult female $n=19$ and saline group: adolescent male $n=23$, adolescent female: $n=19$; adult male: $n=22$; adult female $n=18$.

$\mathrm{mg} / \mathrm{kg}$ of meth caused significant malaise and reduced locomotion by day 3, and therefore for ethical reasons we used $3 \mathrm{mg} / \mathrm{kg}$ that had no observable impact on health.

\subsection{Behavior}

The conditioned place preference/aversion (CPP/CPA) apparatus (Lafayette Instruments, IN, USA) consisted of two main compartments with differences in visual (wall patterns) and tactile (floor texture) cues, separated by a neutral compartment. As per a previous protocol [58], the light intensity settings were set at 30 (80 lux) within the conditioning compartments and 90 ( 380 lux) in the central compartment, with these values referring to the settings on the equipment provided. These settings were chosen to deter mice from remaining in the central compartment. The time spent in each compartment and distance travelled as an indicator for locomotor activity was recorded via horizontal optic sensor beams and specific software for the apparatus (Motor Monitor ${ }^{\mathrm{TM}}$, Kinder Scientific, USA). The CPP protocol and timeline (Figure 1) followed a previously published 4 -day conditioning protocol $[52,57]$ that is relatively short compared to other protocols, to minimize maturation during CPP. Before each session, all cages of mice were moved to the experimental room at the same time and left to habituate for at least $30 \mathrm{~min}$.

In the afternoon on day 1 (baseline), mice were placed in the central compartment and allowed free access to all three compartments. We used an unbiased approach to allocate meth-associated chamber. On days $2-5$ (conditioning), mice received an i.p. injection of saline (10 ml $/ \mathrm{kg}$ ) in the morning (08:30-11:30) and were immediately confined within one of the two conditioning chambers, and an i.p. injection of either meth ( $3 \mathrm{mg} / \mathrm{kg}$; meth group) or saline (10 $\mathrm{ml} / \mathrm{kg}$; saline group) in the afternoon (12:00-15:00) and were immediately confined into the other conditioning chamber. Timing was controlled so that each mouse had 3.5 hrs elapse between the morning and afternoon injections. Meth was never injected in the morning to avoid its potential influence on the afternoon session. The afternoon injection chamber (in which animals receive either saline or meth) was randomly allocated without an expectation of CPP or CPA. The other chamber served as the morning chamber. Once allocated, chamber designation (morning or afternoon) never changed for the mice. An equal number of mice were conditioned within each chamber for each group. On day 6 (test) afternoon, mice were given free access to all three compartments without any injections. All sessions were $30 \mathrm{~min}$ in duration and occurred at the same time each day for a given mouse.

A total of 181 mice began behavioral training. Preference for the chamber in which they were confined during the conditioning afternoon sessions was calculated by dividing time spent in that chamber by the combined time spent in both main chambers (i.e., preference $\%=$ time in afternoon chamber $/$ total time in both chambers x 100). Using the same criteria as previous research [59], 8 mice demonstrating an initial side preference $>67 \%$ at base- line were not allocated to any group, and were eliminated from further training. Two mice were also excluded as they had a side preference at test $>2.75$ standard deviations (SD) from their group mean. This left 171 mice that completed all testing, which gave the final sizes of saline groups (adolescent male $n=23$, adolescent female: $n=19$; adult male: $n=22$; adult female $n=18$ ) and meth groups (adolescent male $n=27$, adolescent female: $n=19$; adult male: $n=24$; adult female $n=19$ ). No more than 1 mouse per group per litter was used - that is, all mice from each group came from different litters. Due to the novelty of our study examining age and sex differences in behavior, target group size (total $\mathrm{N}=144$ ) for behavior was calculated using $\mathrm{G}^{*}$ Power based on our repeated-measures design with 8 groups, small to medium effect size (Cohen's $\mathrm{f}=0.2$ ), type $1 \& 2$ error rate $=0.05[60]$.

Normalized preference score at test expressed as a percentage change from baseline to test was calculated by subtracting the preference score at baseline from that at test and then dividing the outcome by the preference score at baseline (i.e., $\mathrm{CPP} \%$ change $=(\%$ at test - $\%$ at baseline) / $\%$ at baseline). Acquisition of CPP was defined as change in preference $>10 \%$, aversion was defined as change in preference $<-10 \%$, and neutral was defined as change in preference between $10 \%$ and $-10 \%$. These numbers were chosen because $10 \%$ change appears common in previously published studies, especially for CPA [20, 61-63].

Locomotor data were also collected throughout CPP testing to assess the development of behavioral sensitization. It should be noted that the sample size for CPP locomotor data does not match that of the CPP preference data due to a technical fault, where on certain training days (where the mice were confined to one chamber) the CPP chambers stopped recording locomotion, meaning locomotor data on those days were lost. Those mice were removed completely for repeated-measures locomotion analyses that require data on all days to be present. The final locomotor sample sizes for the saline groups were: adolescent male $n=21$, adolescent female: $n=17$; adult male: $n=21$; adult female $n=17$; and for the meth groups were: adolescent male $n=26$, adolescent female: $n=17$; adult male: $n=24$; adult female $n=16$.

\subsection{Tissue collection and immunohistochemistry}

Following a previous learning-related c-Fos protocol in the mice used in the present study [64], ninety min following the start of the test session, mice were anesthetized with sodium pentobarbitone $(100 \mathrm{mg} / \mathrm{kg}$, i.p.) and transcardially perfused with $50 \mathrm{~mL} 0.1$ $M$ phosphate buffered saline (PBS) immediately followed by fixation with $50 \mathrm{~mL} 4 \%$ paraformaldehyde (PFA) in phosphate buffer (PB). Post-fixation in 4\% PFA was $1 \mathrm{~h}$, followed by PB washing (1 $\mathrm{h}$ ) before being transferred into a sucrose solution $(20 \% \mathrm{w} / \mathrm{v}$ in $\mathrm{PB})$ and stored at $4{ }^{\circ} \mathrm{C}$ overnight. Brains were then snap frozen on liquid nitrogen and stored at $-20^{\circ} \mathrm{C}$, before being sectioned into $40 \mu \mathrm{m}$ coronal slices in a 1:4 series using a cryostat (Leica, Germany).

Fluorescent immunohistochemistry was performed to iden- 


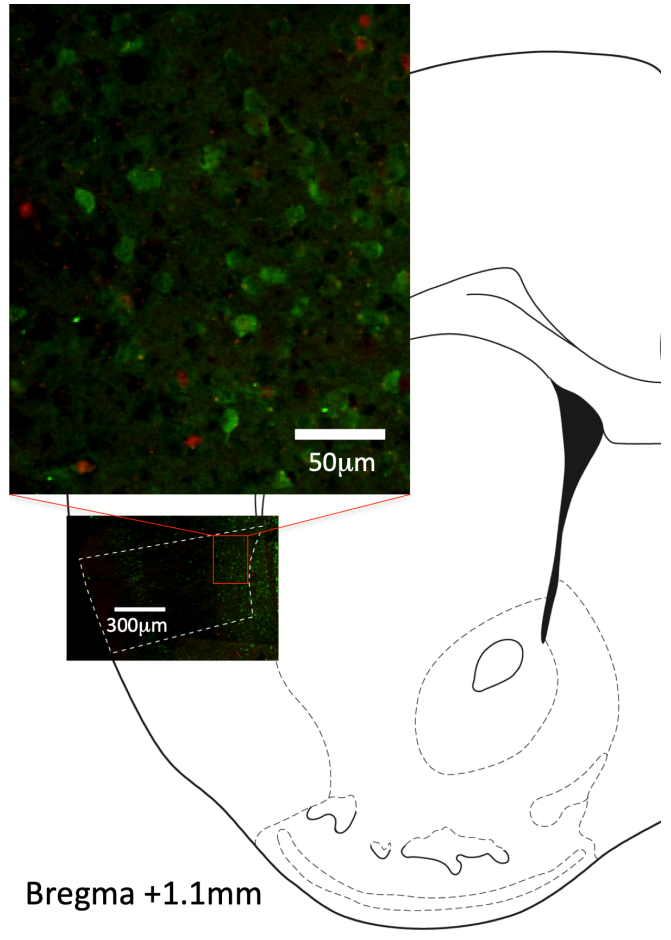

Figure 2. Coronal section of the mouse brain (Bregma $+1.1 \mathrm{~mm}$ ) showing a typical counted section of insular cortex [65]. Immunofluorescence-stained density of cells positively labelled for D1 or D2 (green), c-Fos (red), and D1 or D2/c-Fos colabelled (green with red centre) were quantified using stereology.

tify c-Fos and EGFP tagged D1+ or D2+ cells (Figure 2). Target group size (total $\mathrm{N}=84$ ) were calculated using $\mathrm{G} *$ Power based on between-subjects design with 16 groups (D1 vs D2 genotype is an added factor compared to behavior), and type $1 \& 2$ error rate $=$ 0.05 [60]. Medium effect size (Cohen's $\mathrm{f}=0.4$ ) was chosen based on a previous study examining c-Fos following behavior in Drd1aEGFP and Drd2-EGFP mice [64]. The final sample sizes were - D1 adolescents: male saline $n=6$; male meth $n=6$; female saline $n=6$; female meth $n=6$; D1 adults: male saline $n=6$; male meth $n=6$; female saline $n=6$; female meth $n=6$; D2 adolescent: male saline $n=6$; male meth $n=6$; female saline $n=6$; female meth $n=6$; D2 adults: male saline $n=4$; male meth $n=7$; female saline $n=6$, female meth $n=6$.

Sections were washed in PBS $(3 \times 5 \mathrm{~min})$, and then incubated for $30 \mathrm{~min}$ in a blocking solution (10\% normal donkey serum (NDS) and $0.3 \%$ Triton X-100 in PBS). Primary incubation was in chicken anti-GFP (1: 1000, Abcam, Cambridge, UK, Cat\# ab13970, RRID:AB_300798) and rabbit anti-c-Fos (1 : 2000, Cell Signaling Technology, MA, USA, Cat\# 5348, RRID:AB_10557109) in PBS with $1 \%$ NDS and $0.3 \%$ Triton X-100 for $48 \mathrm{~h}$ on an orbital shaker at $4{ }^{\circ} \mathrm{C}$. Sections were then washed in PBS $(3 \times 5 \mathrm{~min})$ before being incubated for $30 \mathrm{~min}$ in a blocking solution of $10 \%$ NDS and $0.3 \%$ Triton $\mathrm{X}-100$. From this point, sections were always covered in aluminum foil to prevent bleaching of fluorophores. Secondary incubation was on an orbital shaker at room temperature for two hours in donkey anti-chicken (1: 400, Alexa Fluor 488, Jackson ImmunoResearch Labs, PA, USA, Cat\# 703-545-155, RRID: AB_2340375) and donkey anti-rabbit (1 : 400, Alexa Fluor 594, Jackson ImmunoResearch, Cat\# 711-585-152, RRID: AB_2340621) in PBS with $1 \%$ NDS and $0.3 \%$ Triton X-100. After washing in PBS $(3 \times 5 \mathrm{~min})$, sections were mounted onto slides coated in $1 \%$ gelatine, $0.05 \%$ chromium potassium sulphate then were coverslipped using fluorescent mounting medium (Dako, CA, USA).
Table 1. Average Stereology Parameters

\begin{tabular}{ll} 
x-interval $(\mu \mathrm{m})$ & 247 \\
y-interval $(\mu \mathrm{m})$ & 176 \\
D1+ or D2+ cells counted per site & 1.3 \\
D1+ or D2+ cells counted per slice & 20 \\
D1+ or D2+ cells CE Scheaffer & 0.1 \\
\hline
\end{tabular}

\subsection{Stereology}

Stereology was performed using a Zeiss Axio Imager M2 (Germany) microscope and Stereo Investigator software (MBF Bioscience, VT, USA). Sections were $160 \mu \mathrm{m}$ apart. The insular cortex was quantified across ten consecutive sections (starting from Bregma $+1.70 \mathrm{~mm}$ ) from the left hemisphere to be consistent with the previous studies using these mice [28, 64]. For each section, the area occupied by each region was delineated using a $2.5 \mathrm{x}$ objective lens (N.A. 0.085) according to the mouse brain atlas [65] and cells were counted using a $63 \times$ objective lens (N.A. 1.4). Cell counts were made within an unbiased counting frame of known area (30 $\mu \mathrm{m} \times 30 \mu \mathrm{m})$ that was superimposed on the image of the tissue sections. The sampling grid size was determined by Stereo Investigator software (MBF Bioscience) such that 20 sites were counted in the most rostral section. Details regarding the average sampling grid size ( $\mathrm{x}-$ and $\mathrm{y}$-interval), number of cells counted per site, number of cells counted per slice, and coefficients of error (CE Scheaffer) are listed in Table 1 . The counting frame was positioned randomly by the Stereo Investigator software, leading to a systematic sample of the area occupied by each region. The researcher was blinded to the genotype, treatment, age, and sex of all samples while counting. The estimated density of immunoreactive cells is expressed as the number per $\mathrm{mm}^{3}$.

\subsection{Data analyses}

All statistical analyses were performed using IBM SPSS Statistics 23 (IBM Corp., NY, USA). Data were normally distributed. To minimize Type I error, behavioral (with the exception of the CPP/CPA proportion data and correlations) and brain data were analyzed with overall three- or four-way ANOVA with all the between subjects factors included, and significant interactions were followed up with post hoc ANOVAs with Bonferroni corrections [66]. Factors were: Age factor refers to adolescents (P49 at baseline) or adults (P70 at baseline), Sex factor refers to male or female, Day factor refers to baseline, conditioning day 1, 2, 3, and 4, or test, Time factor refers to the morning (when all mice received saline) or afternoon (when mice received either saline or meth, depending on their Group) session, Group factor refers to saline-treated mice or meth-treated mice in the afternoon sessions, Chamber factor refers to the morning (saline-paired) or afternoon (salineor meth-paired, depending on their Group) chambers, and Genotype factor refers to D1 or D2 expression. For behavioral data, no effect of Genotype nor interactions involving Genotype were detected, so statistics for behavioral experiments were collapsed over Genotype. Due to many significant two-and three-way interactions, post hoc ANOVAs were necessary. When Time (morning vs afternoon session) interacted with all other factors we did post hoc ANOVAs examining interacting factors in the morning and afternoon sessions separately. When Group was involved in the majority of the interactions, we did post hoc ANOVAs examining the interacting factors per Group. When Day was involved in more interactions than Group, we did post hoc ANOVAs examining the interacting factors in each Day. CPP/CPA proportion data were analyzed using chi-square test of independence. Correlations between behavior and brain were assessed for significance using Pearson correlational analyses. 
Adolescent
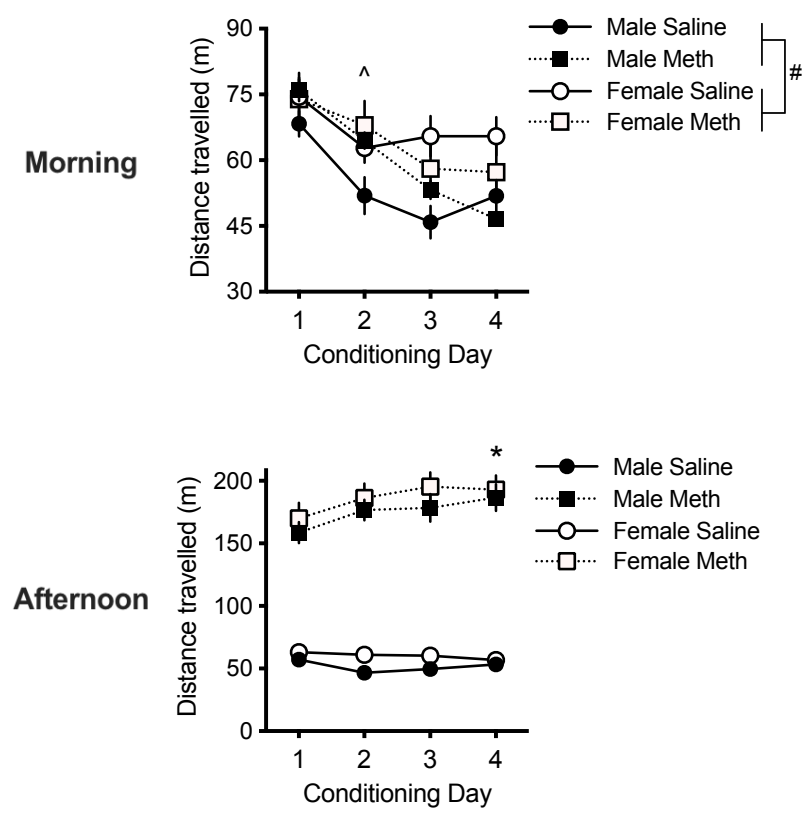

Adult
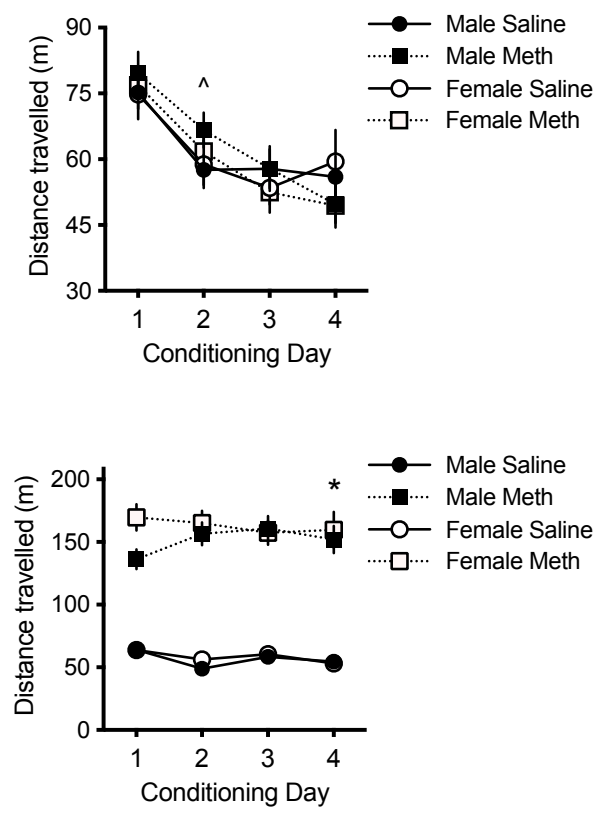

Figure 3. Total distance travelled (m) in the morning session following an acute saline i.p. injection and in the afternoon session following an acute saline or methamphetamine (meth; $3 \mathrm{mg} / \mathrm{kg}$ ) i.p. injection over 4 consecutive days (n=16-26 per group). Post hoc effect of Sex: (\#) p < 0.05. Post hoc effect of Group on day 2 in the morning session: $(\wedge) \mathrm{p}<0.05$. Post hoc effect of Age only in the meth group on day 4 in the afternoon session: $(*) \mathrm{p}<0.05$. Error bars represent \pm SEM.

\section{Results}

\subsection{Locomotion}

Distance travelled (i.e. locomotion) across the conditioning sessions (i.e. days 2-5) were analyzed using a five-way repeated measures (RM) analysis of variance (ANOVA) involving Time, Age, Group, Sex, and Day factors. There were significant effects of Time $(\mathrm{F}(1,151)=426.9, \mathrm{p}<0.001)$, Day $(\mathrm{F}(3,453)=13.0, \mathrm{p}<0.001)$, and Group $(F(1,151)=279.5, p<0.001$; Figure 3$)$. There were also twoway interactions, but they all formed a part of significant threeway interactions: Time $x$ Age $x$ Group $(F(1,151)=5.4, p=0.021)$, Time x Day x Sex $(\mathrm{F}(3,453)=3.8, \mathrm{p}=0.01)$, Time $\mathrm{x}$ Day x Group $(\mathrm{F}(3,453)=15.7, \mathrm{p}<0.001)$, and Day $x$ Group x Sex $(\mathrm{F}(3,453)=2.8$, $\mathrm{p}=0.04$ ). No four- or five-way interactions were detected (smallest $\mathrm{p}=0.14$ ). Because Time interacted with all the other factors, post hoc ANOVAs per Time were conducted to investigate the distance travelled in the morning sessions (when all mice received a saline injection) or the afternoon sessions (when mice received either a saline or meth injection depending on their Group).

A four-way RM ANOVA of the morning locomotor data revealed a significant effect of Day $(\mathrm{F}(3,453)=85.8, \mathrm{p}<0.001)$, and significant Day x Sex $(F(3,453)=3.1, p=0.027)$, Day x Group $(F(3,453)=11.7$, $\mathrm{p}<0.001)$, and Age $x$ Sex $(F(1,151)=4.0, p=0.047)$ interactions. No other effects or interactions were detected (smallest $\mathrm{p}=0.22$ ). This Age $\mathrm{x}$ Sex interaction indicated that averaged across Day and Group, adolescent females moved more than adolescent males $(\mathrm{F}(1,79)=5.6, \mathrm{p}=0.02)$; no significant sex difference was evident in adults $(\mathrm{F}(1,76)=0.3, \mathrm{p}=0.61)$. To understand the Day $\mathrm{x}$ Sex and Day $x$ Group interactions, we analyzed Sex and Group effects in each Day, averaged across ages. These post hoc tests with Bonferroni corrections ( $p$ value cut off: $0.05 / 4$ days $=0.0125$ ) revealed a Group difference only in the second $(\mathrm{F}(1,155)=6.9, \mathrm{p}=0.009)$ morning session, with no other significant Group or Sex effects (smallest $\mathrm{p}=0.027$ ). In the second morning session the meth group moved more than the saline group; that is, mice that received meth for the first time the day before moved more after a saline injection the next morning. Given that both groups show reduced locomo- tion in the second morning session compared to the first morning session, our results suggest the meth group habituated slower on the second day compared to the saline group. In summary, in the chamber that was never paired with meth (morning chamber), female adolescents moved more than male adolescents and there was a transiently delayed locomotor habituation in the meth group compared to saline group.

Analysis of the afternoon locomotor data revealed significant effects of Age $(\mathrm{F}(1,151)=4.6, \mathrm{p}=0.033)$ and Group $(\mathrm{F}(1,151)=445.2$, $\mathrm{p}<0.001)$, and significant Age $x$ Group $(\mathrm{F}(1,151)=5.0, \mathrm{p}=0.027)$, Day x Age $(\mathrm{F}(3,453)=2.9, \mathrm{p}=0.035)$, and Day x Group $(\mathrm{F}(3,453)=10.1$, $\mathrm{p}<0.001)$ interactions; no other effects or interactions were detected (smallest $\mathrm{p}=0.054$ ). Since Group interacted with Age and Day, post hoc tests per Group were conducted with Bonferroni corrections ( $p$ value cut off: $0.05 / 4$ days $=0.0125$ ). Within the saline group, there was no effect of Age in any of the afternoon sessions (smallest $\mathrm{p}=0.30$ ). Within the meth group there was a significant effect of Age only in the fourth $(\mathrm{F}(1,81)=8.5, \mathrm{p}=0.005)$ afternoon session, whereby adolescents travelled further than adults. No effect was found in the other sessions (smallest $\mathrm{p}=0.02$ ). This suggests sensitization of meth-induced hyperlocomotion was greater in adolescent compared to adult mice, regardless of sex.

\subsection{Conditioned place preference/aversion}

A four-way RM ANOVA of percentage preference for the afternoon chamber at baseline vs test between Age, Group, and Sex revealed a significant effect of Group $(F(1,163)=49.9 ; \mathrm{p}<0.001)$ and a significant Day x Group interaction $(F(1,163)=7.2 ; p=0.008)$. No other effects or interactions were detected (smallest $\mathrm{p}=0.056$ ). To understand this Day x Group interaction, the effect of Day was assessed in each Group. In the saline group, Day had no significant effect $(F(1,81)=0.1 ; p=0.72)$. In the meth group, there was a significant effect of Day $(\mathrm{F}(1,88)=11.5 ; \mathrm{p}=0.001)$ whereby preference was higher at test compared to baseline (Figure 4a). This indicates that on average, mice treated with $3 \mathrm{mg} / \mathrm{kg}$ meth formed a preference to the meth-paired chamber. 
a

\section{0
0
0
$\frac{0}{0}$
$\frac{0}{0}$
$\frac{0}{0}$
0
$\frac{1}{0}$
$\frac{0}{0}$
$\frac{0}{0}$
0
$\frac{1}{0}$
$\frac{0}{0}$
$\frac{1}{4}$}

Adolescent
Adult

- Baseline

- Test<smiles>CCC</smiles>

\section{b}

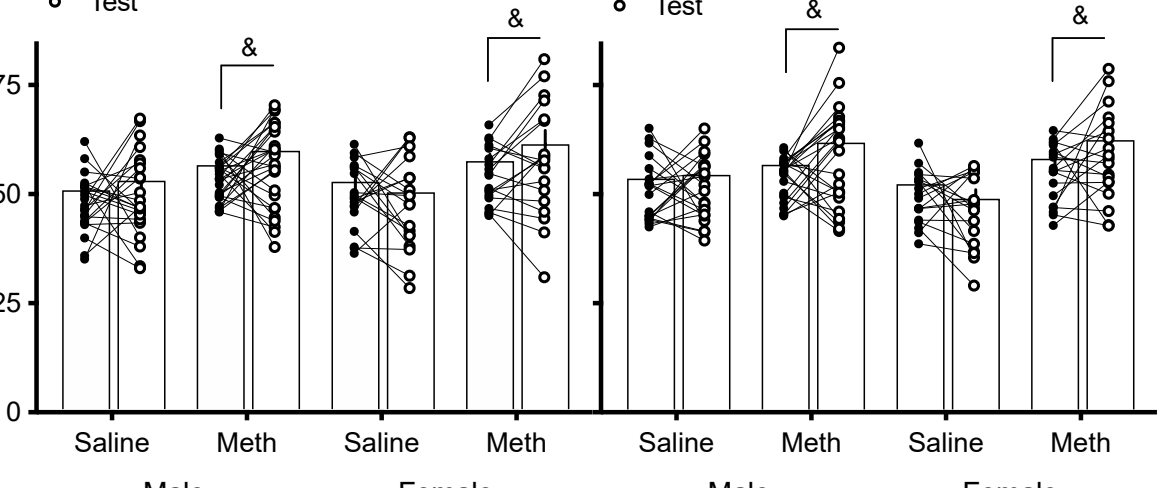

Male

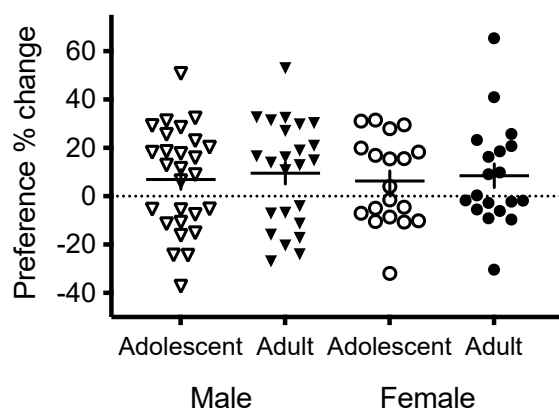

C

Female
\&
- Baseline

- Test

Male

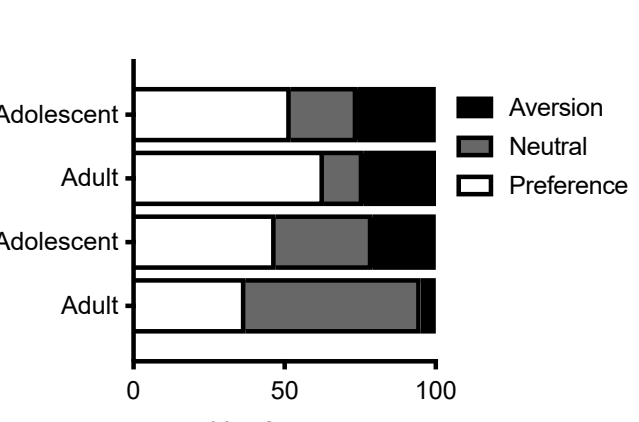

Male

Female

$\%$ of group

Figure 4. (a) Individual conditioned place preference (CPP) \% formed by saline-treated and methamphetamine (meth)-treated mice at test ( $n=18$-27 per group). Preference for the afternoon chamber was calculated by dividing time spent in that chamber by the combined time spent in both chambers (i.e., preference $\%=$ time in afternoon chamber / time in afternoon and morning chambers x 100). Main effect of Day only in meth Group: (\&) p<0.05. (b) Normalized preference score at test expressed as a percentage change from baseline to test in meth-treated mice only ( $n=19-27$ per group). Percentage change was calculated by subtracting the preference score at baseline from that at test and then dividing this figure by the preference score at baseline (i.e., preference $\%$ change $=(\%$ at test $-\%$ at baseline $) / \%$ at baseline $)$. Error bars represent mean \pm SEM. (c) Proportion of mice ( $n=19-27$ per group) that formed a preference (preference $\%$ change $>10 \%$ ), remained neutral (preference $\%$ change between $10 \%$ and $-10 \%)$, and formed an aversion (preference $\%$ change $<-10 \%$ ) to the meth $(3 \mathrm{mg} / \mathrm{kg}$ i.p.)-paired chamber at test. Effect of Sex: $(\#) \mathrm{p}<0.05$.

Based on the evidence of CPP in the meth but not saline group, normalized preference score at test calculated as a percentage change compared to baseline was analyzed in the meth group only examining the effects of Age and Sex. Two-way ANOVA revealed no main effects or an interaction (smallest $\mathrm{p}=0.60$; Figure $4 \mathrm{~b}$ ), however, we observed from normalized data that there was clear evidence of mice that formed aversion. Therefore, we converted this information into frequency statistics and compared groups on the proportion of meth-treated mice that formed a preference (defined as change in preference $>10 \%$ ), remained neutral (defined as change in preference between $10 \%$ and $-10 \%$ ), and formed an aversion (defined as change in preference $<-10 \%$ ) to the meth-paired chamber using chi-square test of independence. These numbers were chosen because $10 \%$ change is common in previously published studies, especially for CPA [20, 61-63]. This revealed a significant effect of Sex $\left(\chi^{2}(2)=8.0, p=0.018\right)$ but no effect of Age $\left(\chi^{2}(2)=1.0, p=0.61\right.$; Figure $\left.4 c\right)$. This suggests that females are more likely to remain neutral compared to males after four days of conditioning with $3 \mathrm{mg} / \mathrm{kg}$ meth.

\subsection{D1+ versus $\mathrm{D} 2+$ cell density}

D1+ versus D2+ cell density in the insula were analyzed by fourway ANOVA examining the effects of Genotype, Age, Group, and Sex, which revealed a significant main effect of $\operatorname{Sex}(F(1,80)=19.4$, $\mathrm{p}<0.001$ ), suggesting that males had a greater density of dopamine receptor expressing cells (Figure 5a). There were significant two- way interactions, however, they formed a part of a four-way interaction of Genotype x Sex x Age x Group $(F(1,80)=8.8, p=0.004)$. No other main effects or interactions were detected (smallest $\mathrm{p}=0.052$ ). To understand this interaction, effects of Sex, Age, and Group were analyzed per Genotype.

In the Drd1a-EGFP (D1) genotype, there was a significant interaction of Sex x Age $(F(1,41)=4.8, p=0.034)$. No other effects or interactions were detected (smallest $\mathrm{p}=0.074$ ). To understand the interaction, we analyzed the effect of Age in each Sex (averaged across Group), which revealed a significant effect of Age in females $(\mathrm{F}(1,22)=8.9, \mathrm{p}=0.007)$ but not in males $(\mathrm{p}=0.50)$. These results suggest female adolescents have higher insula D1+ density than female adults, regardless of drug history.

In the Drd2a-EGFP (D2) genotype, there were significant effects of Age $(F(1,39)=8.8, \mathrm{p}=0.005)$ and $\operatorname{Sex}(F(1,39)=19.9, \mathrm{p}<0.001)$. There were also significant Sex $x$ Age $(F(1,39)=8.7, p=0.005)$ and Sex x Age x Group $(F(1,39)=5.5, p=0.024)$ interactions. No other effects or interactions were detected (smallest $\mathrm{p}=0.15$ ). To understand the three-way interaction, we analyzed the effect of Age and Group in each Sex. For males, adults had more D2+ than adolescents in the meth group $(\mathrm{F}(1,11)=17.5, \mathrm{p}=0.002)$ but not in the saline group ( $\mathrm{p}=0.35)$. There were no effects in females (smallest $\mathrm{p}=0.080$ ). These results suggest that meth exposure lead to higher insula D2+ density in adults compared to adolescents in males only.

A previous study showed that the ratio of D1+ cell density compared to $\mathrm{D} 2+$ cell density was mediated by sex in adolescence but not adulthood [28]. Ratio was calculated by dividing the D1+ 


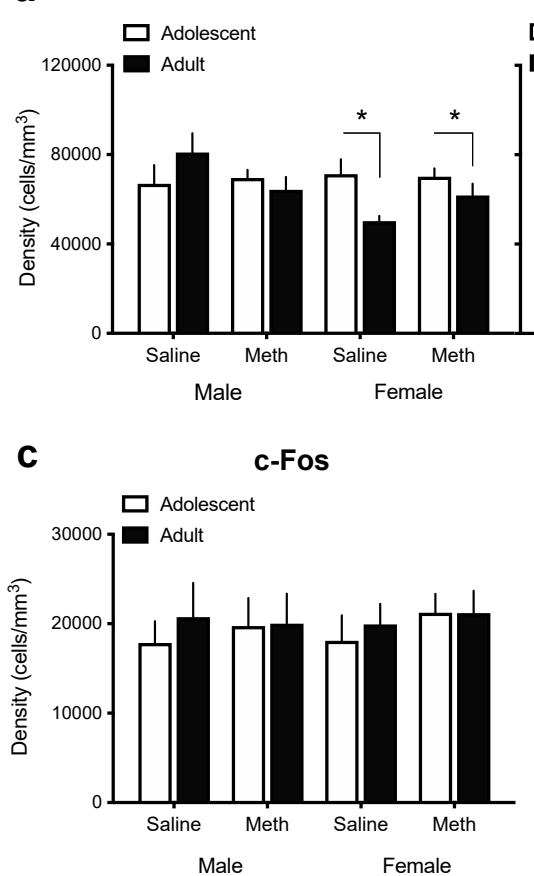

D2

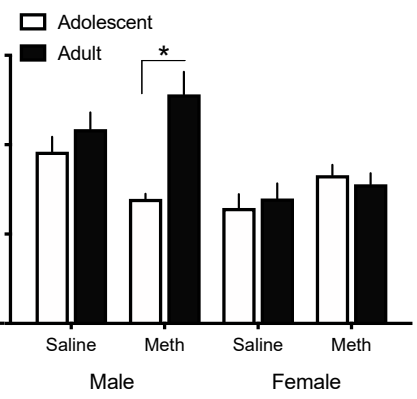

b

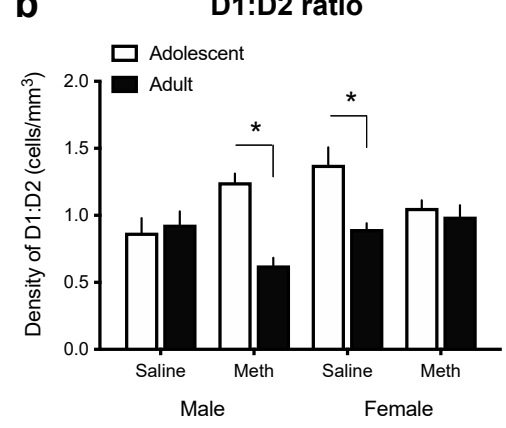

d

D1/c-Fos

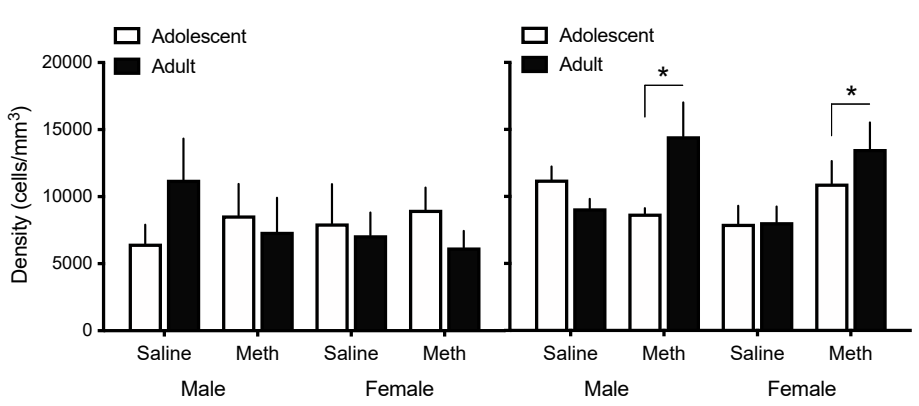

Figure 5. The density (cells $/ \mathrm{mm}^{3}$ ) of (a) dopamine receptor 1 (D1) + and 2 (D2)+ expressing cells, (b) D1+ expressing cells normalized to the average number of D2+ expressing cells (i.e., D1:D2 ratio), (c) c-Fos+ expressing cells, and (d) D1+/c-Fos+ and D2+/c-Fos+ co-labelled cells in the insular cortex (insula) of saline-treated and methamphetamine (meth)-treated mice ( $n=4-7$ per group). Post hoc effect of Age: $(*) p<0.05$. Error bars represent mean + SEM.

density with the average D2+ density in each group to indicate score above 1 as D1 dominance, and below 1 as D2 dominance. A three-way ANOVA examining the effects of Age, Group, and Sex revealed a significant effect of Age $(F(1,41)=21.0, \mathrm{p}<0.001)$ and Sex $(\mathrm{F}(1,41)=7.3, \mathrm{p}=0.01)$, and a significant Age $\mathrm{x}$ Group $\mathrm{x}$ Sex interaction $(\mathrm{F}(1,41)=19.7, \mathrm{p}<0.001$; Figure $5 \mathrm{~b})$. To understand this interaction, analyses were conducted per Group.

In the saline group there was a significant effect of Age $(\mathrm{F}(1,21)=4.6, \mathrm{p}=0.044)$ and $\operatorname{Sex}(\mathrm{F}(1,21)=5.9, \mathrm{p}=0.024)$ and a signif icant Age $x$ Sex interaction $(F(1,21)=6.8, p=0.016)$. Follow-up analyses were conducted per Sex, which revealed a significant effect of Age in female $(\mathrm{F}(1,10)=12.3, \mathrm{p}=0.006)$ but not male $(\mathrm{p}=0.75)$ salinetreated mice. In the meth-treated group there was a significant effect of Age $(F(1,20)=26.4, p<0.001)$ and a significant Age $x$ Sex interaction $(F(1,20)=17.3, p<0.001)$. No effect of Sex was detected $(p=0.21)$. Follow-up analyses were conducted per Sex, which revealed a significant effect of Age in male $(F(1,10)=51.4, p<0.001)$ but not female $(\mathrm{p}=0.54)$ meth-treated mice. This suggests that in meth-treated males but not females, adolescents have a higher D1:D2 ratio than adults. Conversely, in saline-treated females but not males, adolescents have a higher D1:D2 ratio than adults.

\section{4. c-Fos+ cell density}

A three-way ANOVA of c-Fos+ cell density examining the effects of Age, Group, and Sex in the insula revealed no significant effects or interactions (smallest $\mathrm{p}=0.50$; Figure $5 \mathrm{c}$ ), suggesting that Fos density was not affected by conditioning in any of the subjects in this study.

\subsection{D1+/c-Fos+ and D2+/c-Fos+ co-labeled cell density}

A three-way ANOVA of the density of D1+/c-Fos+ co-labelled cells in the insula examining the effects of Age, Group, and Sex revealed no significant effects or interactions (smallest $\mathrm{p}=0.23$; Figure $5 \mathrm{~d}$ ). On the other hand, for D2+/c-Fos+ cells there was a significant ef- fect of Group $(\mathrm{F}(1,39)=5.9, \mathrm{p}=0.02)$ and a significant Age $\mathrm{x}$ Group interaction $(\mathrm{F}(1,39)=5.0, \mathrm{p}=0.031)$. No other effects or interactions were detected (smallest $\mathrm{p}=0.18$ ). Post hoc tests showed that (averaged across Sex) in the saline group there was no difference in $\mathrm{D} 2+/ \mathrm{c}-\mathrm{Fos}+$ density between adolescent and adult mice $(\mathrm{p}=0.40)$. In the meth group, however, adolescents had a significantly lower $\mathrm{D} 2+/ \mathrm{c}-\mathrm{Fos}+$ co-labelled density compared to adults $(\mathrm{F}(1,23)=5.2$, $\mathrm{p}=0.032$ ). Therefore, in both sexes, meth exposure led to increased activation of $\mathrm{D} 2+$ cells in adults compared to adolescents.

3.6. Correlations between preference score and the density of D1+, D2+, and c-Fos+ cells

Given the significant individual differences observed in behavior, we further examined potential relationships between behavior and brain using Pearson correlational analyses separated by Age and Group. Variables examined were \% preference at baseline and test, D1 + and D2+ cell density, c-Fos+ cell density, D1+/c-Fos+ and $\mathrm{D} 2+/ \mathrm{c}-$ Fos + co-labeled cell density.

Surprisingly, saline adult group showed a significant correlation (Table 2). D1+ density was positively correlated with percentage preference for afternoon chamber at test in adults (Figure 6). No other significant correlations were observed (smallest $\mathrm{p}=0.59$ ). Further, no significant correlations were observed in meth-treated adult and adolescent mice (smallest $\mathrm{p}=0.058$; Table 4 \& Table 5).

\section{Discussion}

The present study showed that while mice overall formed a preference for a chamber paired with $3 \mathrm{mg} / \mathrm{kg}$ meth, females were more likely to remain neutral compared to males. No age differences were observed. Conditioning with meth led to age differences in insula D1:D2 ratio for males while reducing age differences in females, and increased c-Fos labeling in insula D2 expressing cells 
Table 2. Pearson Correlation $r$ values between behavior and brain in adult saline-treated mice.

\begin{tabular}{|c|c|c|c|c|c|}
\hline & c-Fos+ & D1+ density & D1+/c-Fos+ density & D2+ density & D2+/c-Fos+ density \\
\hline $\begin{array}{l}\text { Preference at } \\
\text { baseline }\end{array}$ & $\begin{array}{l}r(21)=-0.351, \\
p=0.100\end{array}$ & $r(11)=0.112, p=0.715$ & $\begin{array}{l}r(11)=-0.267 \\
p=0.378\end{array}$ & $r(8)=0.041, p=0.911$ & $r(8)=-0.316, p=0.373$ \\
\hline Preference at test & $\begin{array}{l}r(21)=0.162 \\
p=0.460\end{array}$ & $\begin{array}{l}r(11)=0.671^{*} \\
p=0.012\end{array}$ & $r(11)=0.500, p=0.082$ & $r(8)=0.109, p=0.764$ & $\begin{array}{l}r(8)=-0.614 \\
p=0.059\end{array}$ \\
\hline
\end{tabular}

(*) $\mathrm{p}<0.025$ (Bonferroni corrected)

Table 3. Pearson Correlation $r$ values between behavior and brain in adolescent saline-treated mice.

\begin{tabular}{llllll}
\hline & c-Fos + & D1+ density & D1+/c-Fos+ density & D2+ density & D2+/c-Fos+ density \\
\hline Preference at test & $\mathrm{r}(22)=-0.102$, & $\mathrm{r}(10)=0.123, \mathrm{p}=0.703$ & $\mathrm{r}(10)=0.041$, & $\mathrm{r}(10)=0.339, \mathrm{p}=0.281$ & $\mathrm{r}(10)=0.118, \mathrm{p}=0.715$ \\
& $\mathrm{p}=0.634$ & $\mathrm{p}=0.900$ & $\mathrm{r}$ & $\mathrm{r}(10)=0.469$, \\
Preference at test & $\mathrm{r}(22)=0.323, \mathrm{p}=0.124$ & $\mathrm{r}(10)=0.410, \mathrm{p}=0.186$ & $\mathrm{r}(10)=0.533, \mathrm{p}=0.075$ & $\mathrm{r}(10)=0.630$, & $\mathrm{p}=0.124$ \\
\hline
\end{tabular}

Table 4. Pearson Correlation $r$ values between behavior and brain in adult meth-treated mice.

\begin{tabular}{|c|c|c|c|c|c|}
\hline & c-Fos+ & D1+ density & D1+/c-Fos+ density & D2+ density & D2+/c-Fos+density \\
\hline $\begin{array}{l}\text { Preference at } \\
\text { baseline }\end{array}$ & $r(23)=0.305, p=0.138$ & $\begin{array}{l}r(10)=-0.137 \\
p=0.672\end{array}$ & $r(10)=0.337, p=0.284$ & $\begin{array}{l}r(11)=-0.088 \\
p=0.775\end{array}$ & $\begin{array}{l}r(11)=-0.342, \\
p=0.252\end{array}$ \\
\hline Preference at test & $r(23)=0.124, p=0.556$ & $\begin{array}{l}r(10)=-0.103 \\
p=0.749\end{array}$ & $r(10)=0.013, p=0.967$ & $\begin{array}{l}r(11)=-0.415 \\
p=0.158\end{array}$ & $\begin{array}{l}r(11)=-0.158 \\
p=0.606\end{array}$ \\
\hline
\end{tabular}

Table 5. Pearson Correlation $r$ values between behavior and brain in adolescent meth-treated mice.

\begin{tabular}{llllll} 
& c-Fos + & D1+ density & D1+/c-Fos+ density & D2+ density & D2+/c-Fos+ density \\
\hline Preference at & $\mathrm{r}(22)=-0.293$, & $\mathrm{r}(10)=-0.561$, & $\mathrm{r}(10)=-0.462$, & $\mathrm{r}(10)=0.133, \mathrm{p}=0.681$ & $\mathrm{r}(10)=0.287, \mathrm{p}=0.365$ \\
baseline & $\mathrm{p}=0.165$ & $\mathrm{p}=0.058$ & $\mathrm{p}=0.131$ & & \\
Preference at test & $\mathrm{r}(22)=-0.003$, & $\mathrm{r}(10)=-0.062$, & $\mathrm{r}(10)=-0.266$, & $\mathrm{r}(10)=0.450, \mathrm{p}=0.142$ & $\mathrm{r}(10)=0.451, \mathrm{p}=0.141$ \\
& $\mathrm{p}=0.990$ & $\mathrm{p}=0.848$ & $\mathrm{p}=0.403$ & & \\
\hline
\end{tabular}

in adults compared to adolescents. Insula activity and expression of D1 and D2 were not correlated to test behavior following conditioning with meth.

\subsection{Meth-induced locomotion, but not conditioned place behavior, is age-dependent}

Contrary to our hypothesis, adolescents were not less likely to form CPA (or more likely to form CPP) to $3 \mathrm{mg} / \mathrm{kg}$ meth compared to adults. This is consistent with the report that adolescent and adult male rats show similar acquisition of meth selfadministration when given $2 \mathrm{~h}$ per day access [67], although when access is increased from 2 to $6 \mathrm{~h}$ sessions, adolescent male rats self-administer significantly more meth compared to adults [68]. Our results suggest that such age effect during extended access of meth self-administration may not be driven by adolescents finding meth less aversive compared to adults.

Rather, age differences were observed in locomotion in the present study, with adolescents displaying enhanced sensitization of meth-induced hyperlocomotion compared to adults. This contrasts with finding that male adults display enhanced hyperlocomotion relative to adolescents induced by $0.5 \mathrm{mg} / \mathrm{kg}$ of meth in rats [69]. In male mice, adults moved more than adolescents when acutely injected with $2 \mathrm{mg} / \mathrm{kg}$, but not $4 \mathrm{mg} / \mathrm{kg}$ of meth [70]. The age effect in our study was observed in the last day of conditioning, suggesting that adolescents showed sensitization whereas adults did not. Adolescents may be less sensitive to the stimulant effects of low doses but more sensitive to high doses of meth, especially with repeated injections.

\subsection{Sex differences in meth CPP/CPA}

While both sexes displayed similar meth CPP at a group level, examination of individual differences revealed that females were more likely to remain neutral compared to males. This is the first data being analyzed on individual changes in meth CPP. The lack of sex differences at the group level agrees with previous research that examined a wide range of meth doses $(0.1-5.6 \mathrm{mg} / \mathrm{kg})$ in adult rats, although large variability was reported [63].

\subsection{Insula and meth exposure}

Conditioning with meth induced an age difference in males such that D1:D2 ratio was higher in adolescents relative to adults, whereas it abolished the higher D1:D2 ratio seen in female adolescents relative to adults in the insula. Meth also led to enhanced activation of D2 expressing cells in adults compared to adolescents. These results suggest insula D2 expression in adulthood changes with meth exposure, though it is not necessarily correlated with the formation of meth-induced CPP. Insula D1 and D2 expression may be more susceptible to changes in adulthood compared to adolescence. It has been shown previously that the number of D2, c-Fos, and c-Fos co-labeled D1 and D2 cells in the prelimbic cortex and infralimbic cortex are altered cumulatively with increasing stimulation in adult mice [64].

In our previous study using naïve mice, male adolescents had a substantially lower D1:D2 ratio compared to adults, whereas female adolescents and adults had a similar D1:D2 ratio [28]. The present study was more invasive in comparison (i.e. daily handling, confinement to chambers, injections). This appears to have 


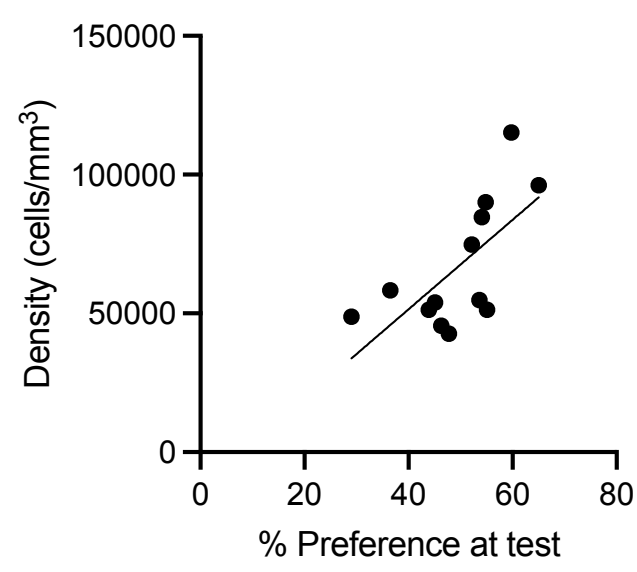

Figure 6. The density (cells $/ \mathrm{mm}^{3}$ ) of dopamine receptor 1 expressing cells insular significantly correlate with afternoon chamber \% preference only in adult saline rats $(r=0.671)$.

reduced D1:D2 ratio in adults compared to Cullity et al. (2019), because in saline mice we found adolescent and adult males had a similar D1:D2 ratio, whereas adolescent females had higher D1:D2 ratio compared to adults (Figure $5 b$ ). Notably, the discrepant results between the present saline mice and naïve mice from Cullity et al. (2019) may also be a result of the age at perfusion. In this study, mice were $\mathrm{P} 54$ and $\mathrm{P} 75$ when perfused; in our previous study, mice were $\mathrm{P} 49$ and $\mathrm{P} 70$ when perfused [28]. Future studies examining D1 and D2 expression in naïve P54 and P75 mice would clarify this potential explanation.

\subsection{Insula and place conditioning with meth}

Despite the significant changes in the insula induced by meth exposure, these changes were not associated with test behavior at group or individual level. For example, the density of c-Fos cells (co-labelled or not) was unrelated to behavior at baseline or test (Tables 2-5), confirming that insula cells are not recruited during the expression of CPP or CPA.

Surprisingly, insula D1 density in saline conditioned adults was positively correlated to their preference for their afternoon chamber at test. Of note, insula D1 density was not associated with the baseline preference, indicating that these effects did not result from their reaction to a novel environment. These data suggest that over numerous days of exposure to distinct environments without any other manipulation, mice may show a nonassociative preference that is related to expression of insula D1 in adulthood. When mice were conditioned with meth, these relations were no longer observed. Too few CPP/CPA studies include and/or report between-subjects saline-saline place preference in relation to insular or other brain regions to be able to meaningfully interpret this finding. Our results highlight the need of more studies to include saline-saline controls to discriminate between associative and non-associative place preference that mice may display. The individual data plots suggest that group interpretation may be misleading in any CPP/CPA studies.

\subsection{Limitations and future directions}

We referred to mid-late adolescent mice as 'adolescents' throughout this study. While these mice were perfused well before the stabilization of hormones that occur in young adulthood (P60) in mice [47], an age effect may have been observed if younger mice were used.

A single high dose of meth was used in the present study. This dose ( $3 \mathrm{mg} / \mathrm{kg}$ ) was the highest dose identified in a pilot experiment to not cause any malaise in these mice. As such, outcomes may be different with lower doses. Studies utilizing $0.125-2 \mathrm{mg} / \mathrm{kg}$ of meth have consistently observed CPP [51, 52, 57, 69, 71], and showed that $0.125-2 \mathrm{mg} / \mathrm{kg}$ of meth induces similar CPP in male adolescent and adult mice and rats [51, 69]. It has been shown in rats that adolescent males form a preference more quickly than adults at 0.5 and $1 \mathrm{mg} / \mathrm{kg}$ of meth [69]. Notably, all those previous studies have been in males only and potential sex- and agedifferences at lower doses of meth remains unexplored. Additionally, more studies should assess individual differences, considering the variability that are often observed in CPP/CPA studies.

Changes in D1 and D2 expression did not appear to be associated with place conditioning with $3 \mathrm{mg} / \mathrm{kg}$ meth. This is consistent with recent meta-analyses showing that dopamine receptor gene polymorphisms may not determine risk towards meth use disorder [72]. Nevertheless, conditioning with meth altered insula D1 and D2 expression, which may subserve changes in behaviors commonly observed following meth use. For example, social cognition impairments in meth users have been shown to be associated with insula hypoactivity $[73,74]$, which would be interesting to establish in mice to target for testing potential therapeutics. Further, protein inhibition of insula after CPP recall or extinction has been shown to prevent CPP expression for upto 24 days [42]. Thus, ageand sex-specific assessment of insula's role in CPP/CPA following extinction appears warranted considering extinction deficits reliably observed in adolescent rodents and humans [75-80].

Lastly, with known involvement of D1 and D2 signaling in CPP and CPA [38, 39], other regions that show age- and sex-differences in D1 and D2 expression should be explored. The present results showing sex but not age differences in meth-induced CPP are consistent with females showing D1 dominance compared to males in the dorsal and ventral striatum regardless of age [28], which implicates areas such as the nucleus accumbens in driving CPP and/or CPA.

\section{Conclusion}

The present study demonstrates that males are more likely to experience a high dose of meth as rewarding or aversive compared to females. Age differences in vulnerability to meth use are potentially not driven by differences in how aversive they experience a high dose of meth. Preference or aversion expressed at test does not appear to be related to insula activity or D1 and D2 expression. Interestingly, we have shown that adults may be more susceptible to change in insula D1 and D2 expression following meth exposure compared to adolescents. D1 and D2 are considered important mediators of adolescent vulnerability to substance use [77, 81-83]. Future experiments should assess sex and age differences in the role of insula in behaviors affected by chronic meth use, such as social cognition, to develop precision medicine for individuals with meth use disorder.

\section{Declarations}

\section{Funding}

This work was supported by the Australian Postgraduate Award (ERC); the Melbourne Research Scholarship from the University of Melbourne (AAG); the National Health and Medical Research Council (NHMRC)/Australian Research Council (ARC) Dementia Research Development Fellowship APP1107144 (CJP); the NHMRC Career Development Fellowship APP1083309 (JHK); and the Victorian State Government Operational Infrastructure Scheme. 
Conflict of Interest

All authors declare no conflicts of interest.

\section{Data Availability}

Data is available on Zenodo [84].

\section{Editorial Notes}

\section{History}

- Received: 2021-06-15

- Revisions Requested: 2021-07-16

- Revisions Received: 2021-08-12

- Accepted: 2021-08-14

- Published: 2021-08-27

\section{Editorial Checks}

- Statistics: statcheck.io did not identify errors.

- Plagiarism: Plagiarism detection software found no evidence of plagiarism.

- References: Zotero did not identify any references in the RetractionWatch database.

\section{Peer Review}

This paper followed a double-blind review process.

For the benefit of readers, reviewers are asked to write a public summary of their review to highlight the key strengths and weaknesses of the paper. Signing of reviews is optional.

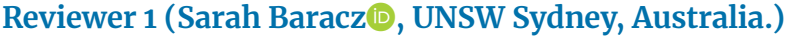

This empirical study investigated whether increased susceptibility for substance misuse is linked to adolescents experiencing fewer aversive effects when using drugs of abuse and if this involves dopamine receptor 1 (D1) or 2 (D2) activation in the insular cortex. The authors incorporated both sexes in their study as well as adolescent and adult genetically modified mice that expressed GFP on either D1 or D2 expressing cells to examine whether mice would develop a conditioned place preference or a conditioned place aversion to a high methamphetamine dose. The authors did not observe a difference in the formation of a conditioned place preference or aversion based on age, although did report a number of sex differences. Altogether, their findings suggest that increased susceptibility for substance abuse is not likely due to adolescents experiencing fewer aversive effects when using meth.

\section{Reviewer 2 (Anonymous)}

This paper examined whether adolescent mice had reduced aversion to a high dose of methamphetamine. The authors also examined the effect of sex on methamphetamine reward/aversion. Additionally the authors examined whether activity at dopamine-1a and dopamine- 2 receptors in the insular cortex was affected by methamphetamine-exposure and/or methamphetamine-related reward/aversion. Overall, the methodology was sound and rigorous allowing the experimenters to test their hypothesis. The results are interesting and an important contribution to the field.

\section{Reviewer 3 - References Review (Anonymous)}

I have checked the paper's references and have found that most the information on each reference is correct and complete, papers have been cited appropriately and the reference list contains only papers in legitimate peer-reviewed sources. I had only a few minor comments where better references were available.

\section{References}

1. United Nations Office On Drugs and Crime. World Drug Report 2016. New York: United Nations Office on Drugs and Crime; 2016. doi: 10.18356/603a2a94-en

2. Degenhardt L, Larney S, Chan G, Dobbins T, Weier M, Roxburgh $\mathrm{A}$, et al. Estimating the number of regular and dependent methamphetamine users in Australia, 2002-2014. The Medical journal of Australia. 2016;204(4):153-6. doi: $10.5694 / \mathrm{mja} 15.00671$.

3. Yimsaard P, Maes MM, Verachai V, Kalayasiri R. Pattern of Methamphetamine Use and the Time Lag to Methamphetamine Dependence. Journal of Addiction Medicine. 2018;12(2):92-98. doi: 10.1097/ADM.0000000000000371.

4. AIHW. National Drug Strategy Household Survey 2019. Canberra, ACT: Australian Institute of Health and Welfare; 2020. doi: 10.25816/e42p-a447.

5. AIHW. National Drug Strategy Household Survey 2016. Canberra, АCT: Australian Institute of Health and Welfare; 2017. doi: 10.25816/5ec5bc1bed176.

6. Compton WM, Thomas YF, Stinson FS, Grant BF. Prevalence, correlates, disability, and comorbidity of DSM-IV drug abuse and dependence in the United States: results from the national epidemiologic survey on alcohol and related conditions. Arch Gen Psychiatry. 2007;64(5):566-76. doi: 10.1001/archpsyc.64.5.566.

7. Papamihali K, Collins D, Karamouzian M, Purssell R, Graham B, Buxton J. Crystal methamphetamine use in British Columbia, Canada: A cross-sectional study of people who access harm reduction services. PloS one. 2021;16(5):e0252090. doi: 10.1371/journal.pone.0252090.

8. Courtney KE, Ray LA. Methamphetamine: an update on epidemiology, pharmacology, clinical phenomenology, and treatment literature. Drug Alcohol Depend. 2014;143:11-21. doi: 10.1016/j.drugalcdep.2014.08.003.

9. Brecht ML, O'Brien A, von Mayrhauser C, Anglin MD. Methamphetamine use behaviors and gender differences. Addictive Behaviors. 2004:29(1):89-106. doi: 10.1016/S03064603(03)00082-0.

10. He J, Xie Y, Tao J, Su H, Wu W, Zou S, et al. Gender differences in socio-demographic and clinical characteristics of methamphetamine inpatients in a Chinese population. Drug Alcohol Depend. 2013;130(1-3):94-100. doi: 10.1016/j.drugalcdep.2012.10.014.

11. Hser YI, Evans E, Huang YC. Treatment outcomes among women and men methamphetamine abusers in California. J Subst Abuse Treat. 2005;28(1):77-85. doi: 10.1016/j.jsat.2004.10.009.

12. Mayo LM, Paul E, DeArcangelis J, Van Hedger K, de Wit H. Gender differences in the behavioral and subjective effects of methamphetamine in healthy humans. Psychopharmacology (Berl). 2019;236(8):2413-2423. doi: 10.1007/s00213-01905276-2.

13. Rawson RA, Gonzales R, Obert JL, McCann MJ, Brethen P. Methamphetamine use among treatment-seeking adolescents in Southern California: participant characteristics and treatment response. J Subst Abuse Treat. 2005;29(2):67-74. doi: 10.1016/j.jsat.2005.04.001.

14. Spear LP. The adolescent brain and age-related behav- 
ioral manifestations. Neuroscience \& Biobehavioral Reviews. 2000;24(4):417-463. doi: 10.1016/S0149-7634(00)00014-2.

15. Infurna RN, Spear LP. Developmental changes in amphetamine-induced taste aversions. Pharmacology, Biochemistry and Behavior. 1979;11(1):31-35. doi: 10.1016/00913057(79)90293-4.

16. Shram MJ, Funk D, Li Z, Le AD. Periadolescent and adult rats respond differently in tests measuring the rewarding and aversive effects of nicotine. Psychopharmacology (Berl) 2006;186(2):201-8. doi: 10.1007/s00213-006-0373-8.

17. Schramm-Sapyta NL, Morris RW, Kuhn CM. Adolescent rats are protected from the conditioned aversive properties of cocaine and lithium chloride. Pharmacol Biochem Behav. 2006;84(2):344-52. doi: 10.1016/j.pbb.2006.05.026.

18. Philpot RM, Badanich KA, Kirstein CL. Place conditioning: age-related changes in the rewarding and aversive effects of alcohol. Alcohol Clin Exp Res. 2003;27(4):593-9. doi: 10.1097/01.ALC.0000060530.71596.D1.

19. Wilmouth CE, Spear LP. Adolescent and adult rats' aversion to flavors previously paired with nicotine. Ann N Y Acad Sci. 2004;1021:462-4. doi: 10.1196/annals.1308.065.

20. Su ZI, Santoostaroam A, Wenzel J, Ettenberg A. On the persistence of cocaine-induced place preferences and aversions in rats. Psychopharmacology (Berl). 2013;229(1):115-23. doi: 10.1007/s00213-013-3086-9.

21. Anderson RI, Agoglia AE, Morales M, Varlinskaya EI, Spear LP. Stress, kappa manipulations, and aversive effects of ethanol in adolescent and adult male rats. Neuroscience. 2013;249:21422. doi: 10.1016/j.neuroscience.2012.12.028.

22. Budzynska B, Polak P, Biala G. Effects of calcium channel antagonists on the motivational effects of nicotine and morphine in conditioned place aversion paradigm. Behav Brain Res. 2012;228(1):144-50. doi: 10.1016/j.bbr.2011.12.003.

23. Kim JH, Perry CJ, Ganella DE, Madsen HB. Postnatal development of neurotransmitter systems and their relevance to extinction of conditioned fear. Neurobiol Learn Mem. 2017;138:252-270. doi: 10.1016/j.nlm.2016.10.018.

24. Weickert CS, Webster MJ, Gondipalli P, Rothmond D, Fatula RJ, Herman MM, et al. Postnatal alterations in dopaminergic markers in the human prefrontal cortex. NSC. 2007;144(3):1109-1119. doi: 10.1016/j.neuroscience.2006.10.009.

25. Rothmond DA, Weickert CS, Webster MJ. Developmental changes in human dopamine neurotransmission: cortical receptors and terminators. BMC Neuroscience. 2012;13(1):18. doi: 10.1186/1471-2202-13-18.

26. Caballero A, Granberg R, Tseng KY. Mechanisms contributing to prefrontal cortex maturation during adolescence. Neuroscience \&amp; Biobehavioral Reviews. 2016;70:4-12. doi: 10.1016/j.neubiorev.2016.05.013.

27. Luikinga SJ, Kim JH, Perry CJ. Developmental perspectives on methamphetamine abuse: Exploring adolescent vulnerabilities on brain and behavior. Prog Neuropsychopharmacol Biol Psychiatry. 2018;87(Pt A):78-84. doi: 10.1016/j.pnpbp.2017.11.010.

28. Cullity ER, Madsen HB, Perry CJ, Kim JH. Postnatal developmental trajectory of dopamine receptor 1 and 2 expression in cortical and striatal brain regions. Journal of Comparative Neurology. 2019;527(6):1039-1055. doi: 10.1002/cne.24574.

29. Cullity ER, Bjerke IE, Kjelsberg K, Leergaard TB, Kim JH. Distribution of dopamine 1 receptor positive neurons in the adult female mouse brain. EBRAINS. 2020;doi: 10.25493/5MXRAW7.

30. Cullity ER, Bjerke IE, Kjelsberg K, Leergaard TB, Kim JH. Distribution of dopamine 1 receptor positive neurons in the adult male mouse brain. EBRAINS. 2020;doi: 10.25493/AVRZ-4JB.

31. Cullity ER, Bjerke IE, Kjelsberg K, Leergaard TB, Kim JH. Distribution of dopamine 1 receptor positive neurons in the late adolescent female mouse brain. EBRAINS. 2020;doi: 10.25493/31D4-SKG.

32. Cullity ER, Bjerke IE, Kjelsberg K, Leergaard TB, Kim JH. Distribution of dopamine 1 receptor positive neurons in the late adolescent male mouse brain. EBRAINS. 2020;doi: 10.25493/GVFP-10X.

33. Cullity ER, Bjerke IE, Kjelsberg K, Leergaard TB, Kim JH. Distribution of dopamine 2 receptor positive neurons in the adult female mouse brain. EBRAINS. 2020;doi: 10.25493/VTDo-D15.

34. Cullity ER, Bjerke IE, Kjelsberg K, Leergaard TB, Kim JH. Distribution of dopamine 2 receptor positive neurons in the adult male mouse brain. EBRAINS. 2020;doi: 10.25493/4DEB-5AJ.

35. Cullity ER, Bjerke IE, Kjelsberg K, Leergaard TB, Kim JH Distribution of dopamine 2 receptor positive neurons in the late adolescent female mouse brain. EBRAINS. 2020;doi: 10.25493/JJYX-T5R.

36. Cullity ER, Bjerke IE, Kjelsberg K, Leergaard TB, Kim JH. Distribution of dopamine 2 receptor positive neurons in the late adolescent male mouse brain. EBRAINS. 2020;doi: 10.25493/ANPQ-05J.

37. Kebabian JW, Calne DB. Multiple receptors for dopamine. Nature. 1979;277(5692):93-6. doi: 10.1038/277093ao.

38. Hoffman DC, Beninger RJ. Selective D1 and D2 dopamine agonists produce opposing effects in place conditioning but not in conditioned taste aversion learning. Pharmacology, Biochemistry and Behavior. 1988;31(1):1-8. doi: 10.1016/00913057(88)90302-4.

39. White NM, Packard MG, Hiroi N. Place conditioning with dopamine D1 and D2 agonists injected peripherally or into nucleus accumbens. Psychopharmacology. 1991;103:271-276. doi: 10.1007/BF02244216.

40. Hoffman DC, Beninger RJ. The effects of selective dopamine D1 or D2 receptor antagonists on the establishment of agonistinduced place conditioning in rats. Pharmacol Biochem Behav. 1989;33(2):273-9. doi: 10.1016/0091-3057(89)90499-1.

41. Vinish M, Elnabawi A, Milstein JA, Burke JS, Kallevang JK, Turek KC, et al. Olanzapine treatment of adolescent rats alters adult reward behaviour and nucleus accumbens function. Int J Neuropsychopharmacol. 2013;16(7):1599-609. doi: 10.1017/S1461145712001642.

42. Contreras M, Billeke P, Vicencio S, Madrid C, Perdomo G, González M, et al. A role for the insular cortex in long-term memory for context-evoked drug craving in rats. Neuropsychopharmacology. 2012;37(9):2101-2108. doi: 10.1038/npp.2012.59.

43. Gong S, Zheng C, Doughty ML, Losos K, Didkovsky N, Schambra UB, et al. A gene expression atlas of the central nervous system based on bacterial artificial chromosomes. Nature. 2003;425(6961):917-25. doi: 10.1038/nature02033.

44. Madsen HB, Kim JH. Ontogeny of memory: An update on 40 years of work on infantile amnesia. Behav Brain Res. 2016;298(Pt A):4-14. doi: 10.1016/j.bbr.2015.07.030.

45. Darke S, Kaye S, Torok M. Age-related patterns of drug use initiation among polydrug using regular psychostimulant users. Drug Alcohol Rev. 2012;31(6):784-9. doi: 10.1111/j.14653362.2012.00436.x.

46. Gaytan F, Morales C, Leon S, Heras V, Barroso A, Avendano MS, et al. Development and validation of a method for precise dating of female puberty in laboratory rodents: The puberty ovarian maturation score (Pub-Score). Sci Rep. 2017;7:46381. doi: $10.1038 /$ srep46381.

47. Nelson JF, Karelus K, Felicio LS, Johnson TE. Genetic influences on the timing of puberty in mice. Biol Reprod. 1990;42(4):649-55. doi: 10.1095/biolreprod42.4.649.

48. Tan OL, Fleming JS. Proliferating cell nuclear antigen immunoreactivity in the ovarian surface epithelium of mice of varying ages and total lifetime ovulation number following ovulation. Biol Reprod. 2004;71(5):1501-7. doi: 10.1095/biol- 
reprod.104.030460.

49. Ekambaram G, Sampath Kumar SK, Joseph LD. Comparative Study on the Estimation of Estrous Cycle in Mice by Visual and Vaginal Lavage Method. J Clin Diagn Res. 2017;11(1):AC05AC07. doi: 10.7860/JCDR/2017/23977.9148.

50. Deboer MD, Li Y. Puberty is delayed in male mice with dextran sodium sulfate colitis out of proportion to changes in food intake, body weight, and serum levels of leptin. Pediatr Res. 2011;69(1):34-9. doi: 10.1203/PDR.ob013e3181ffee6c.

51. Kim JH, Lavan D, Chen N, Flores C, Cooper H, Lawrence AJ. Netrin-1 receptor-deficient mice show age-specific impairment in drug-induced locomotor hyperactivity but still selfadminister methamphetamine. Psychopharmacology (Berl). 2013;230(4):607-16. doi: 10.1007/s00213-013-3187-5.

52. Chesworth R, Brown RM, Kim JH, Ledent C, Lawrence AJ. Adenosine $2 \mathrm{~A}$ receptors modulate reward behaviours for methamphetamine. Addiction biology. 2015;21(2):407-421. doi: 10.1111/adb.12225.

53. Vidal-Infer A, Roger-Sanchez C, Daza-Losada M, Aguilar MA, Minarro J, Rodriguez-Arias M. Role of the dopaminergic system in the acquisition, expression and reinstatement of MDMA-induced conditioned place preference in adolescent mice. PloS one. 2012;7(8):e43107. doi: 10.1371/journal.pone.0043107.

54. Kramer PF, Christensen CH, Hazelwood LA, Dobi A, Bock R, Sibley DR, et al. Dopamine D2 receptor overexpression alters behavior and physiology in Drd2-EGFP mice. J Neurosci. 2011;31(1):126-32. doi: 10.1523/JNEUROSCI.4287-10.2011.

55. Nelson AB, Hang GB, Grueter BA, Pascoli V, Luscher C, Malenka RC, et al. A Comparison of Striatal-Dependent Behaviors in Wild-Type and Hemizygous Drd1a and Drd2 BAC Transgenic Mice. Journal of Neuroscience. 2012;32(27):91199123. doi: 10.1523/JNEUROSCI.0224-12.2012.

56. Pandy V, Wai YC, Amira Roslan NF, Sajat A, Abdulla Jallb AH, Vijeepallam K. Methanolic extract of Morinda citrifolia Linn. unripe fruit attenuates methamphetamine-induced conditioned place preferences in mice. Biomed Pharmacother. 2018;107:368-373. doi: 10.1016/j.biopha.2018.08.008.

57. Chesworth R, Brown RM, Kim JH, Lawrence AJ. The metabotropic glutamate 5 receptor modulates extinction and reinstatement of methamphetamine-seeking in mice. PloS one. 2013;8(7):e68371. doi: 10.1371/journal.pone.0068371.

58. Brown RM, Short JL, Lawrence AJ. Identification of brain nuclei implicated in cocaine-primed reinstatement of conditioned place preference: a behaviour dissociable from sensitization. PLoS One. 2010;5(12):e15889. doi: 10.1371/journal.pone.0015889.

59. Su HL, Zhu J, Chen YJ, Zhao N, Han W, Dang Yh, et al. Roles of levo-tetrahydropalmatine in modulating methamphetamine reward behavior. Physiology \& Behavior. 2013;118(C):195-200. doi: 10.1016/j.physbeh.2013.05.034.

60. Faul F, Erdfelder E, Lang AG, Buchner A. G*Power 3: A flexible statistical power analysis program for the social, behavioral, and biomedical sciences. Behavior research methods. 2007;39(2):175-191. doi: 10.3758/BF03193146.

61. Tenk CM, Kavaliers M, Ossenkopp KP. Dose response effects of lithium chloride on conditioned place aversions and locomotor activity in rats. European Journal of Pharmacology. 2005;515(13):117-127. doi: 10.1016/j.ejphar.2005.04.007.

62. Gore-Langton JK, Flax SM, Pomfrey RL, Wetzell BB, Riley AL. Measures of the aversive effects of drugs: A comparison of conditioned taste and place aversions. Pharmacol Biochem Behav. 2015;134(C):99-105. doi: 10.1016/j.pbb.2015.05.002.

63. Schindler CW, Bross JG, Thorndike EB. Gender differences in the behavioral effects of methamphetamine. European Journal of Pharmacology. 2002;442(3):231-235. doi: 10.1016/s00142999(02)01550-9.

64. Madsen HB, Guerin AA, Kim JH. Investigating the role of dopamine receptor- and parvalbumin-expressing cells in extinction of conditioned fear. Neurobiol Learn Mem. 2017;145:7-17. doi: 10.1016/j.nlm.2017.08.009.

65. Franklin KBJ, Paxinos G. The mouse brain in stereotaxic coordinates. Amsterdam; London: Elsevier Academic Press; 2008. OCLC: 845721906.

66. McHugh ML. Multiple comparison analysis testing in ANOVA. Biochemia Medica. 2011;21(3):203-209. doi: 10.11613/bm.2011.029.

67. Luikinga SJ, Perry CJ, Madsen HB, Lawrence AJ, Kim JH. Effects of Methamphetamine Exposure on Fear Learning and Memory in Adult and Adolescent Rats. Neurochem Res. 2019;44(9):2081-2091. doi: 10.1007/s11064-019-02845-x.

68. Anker JJ, Baron TR, Zlebnik NE, Carroll ME. Escalation of methamphetamine self-administration in adolescent and adult rats. Drug and Alcohol Dependence. 2012;124(1-2):149153. doi: 10.1016/j.drugalcdep.2012.01.004.

69. Zakharova E, Leoni G, Kichko I, Izenwasser S. Differential effects of methamphetamine and cocaine on conditioned place preference and locomotor activity in adult and adolescent male rats. Behav Brain Res. 2009;198(1):45-50. doi: 10.1016/j.bbr.2008.10.019.

70. Zombeck JA, Gupta T, Rhodes JS. Evaluation of a pharmacokinetic hypothesis for reduced locomotor stimulation from methamphetamine and cocaine in adolescent versus adult male C57BL/6J mice. Psychopharmacology (Berl). 2009;201(4):589-99. doi: 10.1007/s00213-008-1327-0.

71. Xu P, Qiu Y, Zhang Y, Bai Y, Xu P, Liu Y, et al. The Effects of 4-Methylethcathinone on Conditioned Place Preference, Locomotor Sensitization, and Anxiety-Like Behavior: A Comparison with Methamphetamine. The international journal of neuropsychopharmacology / official scientific journal of the Collegium Internationale Neuropsychopharmacologicum (CINP). 2016;19(4). doi: 10.1093/ijnp/pyv120.

72. Guerin AA, Nestler EJ, Berk M, Lawrence AJ, Rossell SL, Kim JH. Genetics of methamphetamine use disorder: A systematic review and meta-analyses of gene association studies. Neurosci Biobehav Rev. 2021;120:48-74. doi: 10.1016/j.neubiorev.2020.11.001.

73. Guerin AA, Bonomo Y, Lawrence AJ, Baune BT, Nestler EJ, Rossell SL, et al. Cognition and Related Neural Findings on Methamphetamine Use Disorder: Insights and Treatment Implications From Schizophrenia Research. Front Psychiatry. 2019;10:880. doi: 10.3389/fpsyt.2019.00880.

74. Kim YT, Song HJ, Seo JH, Lee JJ, Lee J, Kwon DH, et al. The differences in neural network activity between methamphetamine abusers and healthy subjects performing an emotion-matching task: functional MRI study. NMR Biomed. 2011;24(10):1392-400. doi: 10.1002/nbm.1702.

75. Brenhouse HC, Andersen SL. Delayed extinction and stronger reinstatement of cocaine conditioned place preference in adolescent rats, compared to adults. Behavioral neuroscience. 2008;122(2):460-465. doi: 10.1037/0735-7044.122.2.460.

76. Guerin AA, Zbukvic IC, Luikinga SJ, Drummond KD, Lawrence AJ, Madsen HB, et al. Extinction and drug-induced reinstatement of cocaine seeking following self-administration or conditioned place preference in adolescent and adult rats. Developmental Psychobiology. 2020;5(12):1-13. doi: 10.1002/dev.22017.

77. Zbukvic IC, Kim JH. Divergent prefrontal dopaminergic mechanisms mediate drug- and fear-associated cue extinction during adolescence versus adulthood. Eur Neuropsychopharmacol. 2018;28(1):1-12. doi: 10.1016/j.euroneuro.2017.11.004.

78. Kim JH, Li S, Richardson R. Immunohistochemical analyses of long-term extinction of conditioned fear in adolescent rats. Cereb Cortex. 2011;21(3):530-8. doi: 10.1093/cercor/bhq116.

79. Pattwell SS, Duhoux S, Hartley CA, Johnson DC, Jing D, Elliott $\mathrm{MD}$, et al. Altered fear learning across development 
in both mouse and human. Proc Natl Acad Sci U S A. 2012;109(40):16318-23. doi: 10.1073/pnas.1206834109.

80. Ganella DE, Drummond KD, Ganella EP, Whittle S, Kim JH. Extinction of Conditioned Fear in Adolescents and Adults: A Human fMRI Study. Front Hum Neurosci. 2018;11:647. doi: 10.3389/fnhum.2017.00647.

81. Naneix F, Marchand AR, Pichon A, Pape JR, Coutureau E. Adolescent Stimulation of D2 Receptors Alters the Maturation of Dopamine-dependent Goal-Directed Behavior. Neuropsychopharmacology. 2013;38(8):1566-1574. doi: 10.1038/npp.2013.55.

82. Perreault ML, O'Dowd BF, George SR. Dopamine $\mathrm{D}_{1}-\mathrm{D}_{2}$ receptor heteromer regulates signaling cascades involved in addiction: potential relevance to adolescent drug susceptibility. Developmental neuroscience. 2014;36(3-4):287-296. doi: $10.1159 / 000360158$.

83. Zbukvic IC, Ganella DE, Perry CJ, Madsen HB, Bye CR, Lawrence AJ, et al. Role of Dopamine 2 Receptor in Impaired Drug-Cue Extinction in Adolescent Rats. Cereb Cortex. 2016;26(6):2895-904. doi: 10.1093/cercor/bhw051.

84. Cullity ER, Guérin AA, Madsen HB, Perry CJ, Kim JH. Dataset: Insular cortex dopamine 1 and 2 receptors in methamphetamine conditioned place preference and aversion: Age and sex differences. Zenodo. 2021;doi: 10.5281/zenodo.4983499.

\section{Copyright and License}

Copyright (C 2021. Ellen Rose Cullity, Alexandre Arthur Guérin, Heather Bronwyn Madsen, Christina Jennifer Perry, Jee Hyun Kim. Except where otherwise noted, the content of this article is licensed under a Creative Commons Attribution 4.0 International License. You are free to reuse or adapt this article for any purpose, provided appropriate acknowledgement is provided. For additional permissions, please contact the corresponding author. 